\title{
Tourism demand and economic growth in Spain: New insights based on the yield curve
}

\author{
Daniel Santamaria ${ }^{1}$ and George Filis ${ }^{2}$, \\ ${ }^{1}$ Coventry University, Centre for Financial and Corporate Integrity (CFCI), Gosford \\ Street, CV1 5DL, Coventry, UK. \\ Email: daniel.santamaria@coventry.ac.uk. \\ ${ }^{2}$ Bournemouth University, Department of Accounting, Finance and Economics, \\ Executive Business Centre, 89 Holdenhurst Road, BH8 8EB Bournemouth, UK. \\ Email: gfilis@bournemouth.ac.uk.
}

\begin{abstract}
We examine for the first time the dynamic relationship between tourism growth and expected macroeconomic conditions of the destination country, employing a DCCGARCH model. Our focus is on the Spanish economy and we collect monthly tourist arrival data from five key origin countries, as well as, from around the world between 1998-2017. We capture expected macroeconomic conditions using the Spanish term structure of interest rates. Our findings suggest that the tourism-expected macroeconomic conditions relationship is time-varying without any country-specific differences in the behaviour of the correlations. Importantly, we report that positive correlations coincide with a regime shift in the Spanish economy; whereas negative correlations are evident when expected economic conditions are stable. We further show that the aforementioned relationship is influenced by key geopolitical and economic events (the 2001 terrorist attacks, the Global Financial Crisis and the ECB's quantitative easing programme). We finally report policy implications deriving from our findings.
\end{abstract}

Keywords: Tourism Demand, Yield Curve, DCC-GARCH, Term Structure of Interest Rates, Economic Growth, Spain 


\section{Introduction}

This study aims to shift the focus of the tourism economics literature to the dynamic relationship between tourism growth and expected macroeconomic conditions. The study focuses on Spain given that it is among the top ten (10) destination countries globally in terms of the tourism contribution to its economy (WTTC, 2017). Tourism contributes (both directly and indirectly) in excess of 14\% of Spanish GDP, providing $2.6 \mathrm{~m}$ jobs directly and through related industries, which represents $14 \%$ of the total workforce (WTTC, 2017b). These figures place tourism as the second most important sector in the Spanish economy, only behind the retail industry (WTTC, 2017c).

The importance of the tourism industry on world destinations is well documented in the relevant literature (see, for instance, Cárdenas-García et al., 2015; Dogru and Sirakaya-Turk, 2017; Dogru and Bulut, 2018). It is argued that the importance of the tourism sector to the wider economy stems from the fact the former provides both direct and indirect effects to the latter, in terms of income, employment and infrastructure, among others. Such importance is more prevalent in the European context given the economic effects of the global financial crisis on tourism (Song et al., 2012) and the fact that several EU member-countries are among the top tourism destinations in the world (UNWTO, 2017).

Despite ample evidence on the impact of tourism on economic growth (see, for instance, Lee et al., 2010; Li et al., 2011), such a relationship is by no means conclusive. It is acknowledged that the tourism-led economic growth hypothesis is indeed among the most widely accepted hypothesis in the tourism economics literature (some recent studies include Sugiyarto et al., 2003; Parrilla et al., 2007; Ivanov and Webster, 2013; Dogru and Bulut, 2018). Nevertheless, there is evidence that the conservation hypothesis also holds which maintains that economic conditions are conducive to tourism income generation (see Aslan, 2014; Antonakakis et al., 2017). More recently, authors opine that the feedback hypothesis is able to explain the relationship between tourism income and economic growth, suggesting that there is a strong interdependency among the two (see, Chen and Chiou-Wei, 2009; Perles-Ribes et al., 2017; Antonakakis et al., 2017, among others). Finally, the neutrality hypothesis, which posits that tourism and economic growth are actually independent, also finds support in some studies (see, for instance, Katircioglou, 2009; Tang and Jang, 2009; Tugcu, 2014).

The aforementioned causal relationships have been largely examined through a variety of econometric techniques, including Autoregressive Distributed Lag (ARDL), 
Vector Error Correction Model (VECM) and Vector AutoRegressive (VAR) models and Granger Causality tests. The variables used in these studies primarily involve tourist arrivals or tourism income (as a proxy for tourism growth) and GDP growth.

Given the extant literature surrounding this research area, it is beyond the scope of this paper to provide a detailed account of existing studies. Rather, the aim is to highlight the three main innovations of this paper. First, this study draws attention to the research on the potential interrelationship between tourism growth and expected (rather than current) macroeconomic (performance) prospects of the destination country. Thus, unlike previous studies that focus their interest on GDP (i.e. current macroeconomic performance) when examining the link between tourism and economic growth, this paper investigates the interdependency between tourism and a key economic leading indicator; namely the yield curve spread or term structure of interest rates, as a proxy for expected macroeconomic prospects. It is noteworthy to mention here that this study refers to the "term structure of interest rates", "yield curve" and "spread" interchangeably throughout the paper.

It is maintained here that the use of leading indicator is capable of revealing important new insights on the link between tourism and economic growth based on two premises. On the one hand, if one anticipates that tourism demand will yield positive effects for a destination economy, then these prospects should be reflected first in yield curve spreads prior to their appearance in the real economy. On the other hand, the paper opines that the tourism sector primarily responds to the anticipated, rather than current, economic conditions. The economic literature has convincingly shown that the yield curve spread is capable of successfully predicting output growth, and thus act as the most desired leading indicator (see, inter alia, Estrella and Mishkin, 1998; Hamilton and Kim, 2002; Rudebusch and Williams, 2009; Christiansen, 2013). From a theoretical standpoint, the usefulness of the term structure of interest rates (or yield curve spread) as a leading economic indicator can be explained by expectations theory ${ }^{1}$, the liquidity

\footnotetext{
${ }^{1}$ According to the expectations theory, long-run interest rates reflect the average current and expected short-run interest rates. Thus, if economic conditions are expected to worsen in the future, then future shortrun interest rates are anticipated to decrease, leading to a decrease of the long-run interest rates today and narrowing of the yield curve spread today.
} 
premium theory ${ }^{2}$ or the theory of intertemporal consumption ${ }^{3}$, among others (see Wheelock and Wohar (2009) for an overview of these theories).

Second, the bulk of the previous studies have used static economic frameworks, which do not allow for the potential dynamic character of the aforementioned relationship. Only a handful of studies have recently concentrated their attention on the time-varying relationship between tourism and economic growth, using frameworks such as the Diebold and Yilmaz spillover index, multivariate GARCH models and rollingwindow Granger causality (Lean and Tang, 2010; Tang and Tan, 2013; Antonakakis et al., 2015; Dragouni et al., 2016). The study contributes to this limited number of studies by employing the Dynamic Conditional Correlation (DCC) model of Engle (2002) to assess the time-varying relationship between tourism growth and the term structure of interest rates as a proxy for expected economic conditions.

Finally, in the spirit of de Oliveira Santos (2009), Gounopoulos et al. (2012) and Chatziantoniou et al. (2015), the present study considers both aggregated and disaggregated tourism demand data to accommodate for any origin-specific effects. It also investigates the effects of the 9/11 terrorist attacks in the US and Global Financial Crisis (GFC) on tourism demand, the term structure of interest rates and the said relationship. Moreover, the Quantitative Easing (QE) programme by the European Central Bank (ECB) on Spanish yield curve spreads is also considered, so to establish whether it has an impact on this relationship.

The results suggest that the tourism-economic growth relationship, based on expected macroeconomic conditions, is time varying and volatile both in sign and magnitude. Furthermore, the time-varying correlations do not reveal any notable differences among the origin countries of the Spanish tourism, with the only exception being Germany's tourist arrivals that exhibit a constant negative relationship with the Spanish term structure of interest rates. More importantly, with the exception of Germany, the evidence suggests that positive correlations arise when there is a regime shift in the Spanish economy (either entering into a recession or boom phase). This is

\footnotetext{
2 The liquidity premium theory posit similar arguments to the expectations theory, although is maintains that long-run interest rates equal the average current and expected short-run interest rates plus a liquidity premium, which increases with the duration of the interest rates.

${ }^{3}$ Intertemporal consumption maintains that there is a relationship between the slope of the yield curve and expected economic activity (Harvey, 1988). Harvey (1988) argues that in the anticipation of a recession, households would sell short-run bonds and purchase long-run bonds, so that they can secure some income during the economic downturn. Once again, the end result is that short-run interest rates will increase, whereas long-run interest rates will decrease today, decreasing the yield curve spread.
} 
suggestive of the fact that the regime change seems to influence the behaviour of tourist arrivals. By contrast, negative correlations tend to prevail during periods that the Spanish economy is at a more permanent state (either in a recession or in economic growth). Finally, the $9 / 11$ attack has a significant impact on the said relationship that is countryspecific in terms of signs and magnitude, a feature that is repeated for the recent GFC and the QE programme.

The rest of the paper is structured as follows. Section 2 presents the econometric framework and Section 3 describes the data of the study. Section 4 analyses the empirical findings, before Section 5 to conclude the study.

\section{Methodology}

\subsection{DCC-GARCH Model}

The econometric framework proposed to investigate the relationship between inbound tourism demand and yield curve spreads in the destination country is the dynamic conditional correlation (DCC) model introduced by Engle (2002). As part of a two-step process, first a generalized autoregressive heteroscedasticity (GARCH) model is utilised to generate standardized residuals. These inputs form the information set used to estimate DCC model coefficients. As such, the DCC-GARCH model avoids the computational complexities of multivariate GARCH models given that the number of coefficients estimated to generate conditional correlation estimates does not depend on the "number of series to be correlated" (Engle, 2002).

The use of GARCH models on international tourism demand is an increasingly common feature in the tourism literature (Chan et al., 2005; Shareef and McAleer, 2005, 2007, 2008, to list a few). Evidence of volatility clusters along with leptokurtosis and skewness observed with tourism demand motivates its use for the purpose of this study (Lorde and Moore, 2008a, 2008b). On the other hand, the use of GARCH models on the term structure of interest rates is motivated by the same stylized characteristics of volatility persistence, skewness and leptokurtosis identified by previous studies on the fixed income markets (Hibbert et al., 2011; Alizadeh and Gabrielsen, 2013). Therefore within this framework, correlation estimates $\left(\rho_{t}\right)$ being time varying, is conditional on

past information denoted as $\Psi_{t-1}$ so that $\rho_{t} \mid \Psi_{t-1}$. As such, this represents a stylized fact that differs from the Constant Conditional Correlation Model of Chang et al., (2009). 
Hence, the multivariate $\operatorname{GARCH}(p, q)$ model for inbound tourism demand $(d)$ and the term structure of interest rates (TSI) of the destination country at time $t$, is as follows:

$$
\begin{gathered}
\mathbf{y}_{t}=\boldsymbol{\eta}_{0}+\boldsymbol{\varepsilon}_{t}, \quad \boldsymbol{\varepsilon}_{t} \mid \Psi_{t-1} \sim N\left(0, \mathbf{H}_{t}\right) \\
\mathbf{H}_{t}=\sigma\left(\mathbf{H}_{t-1}, \mathbf{H}_{t-2}, \ldots, \boldsymbol{\varepsilon}_{t-1}, \boldsymbol{\varepsilon}_{t-2}, \ldots\right)
\end{gathered}
$$

where $\mathbf{y}_{t}$ is the vector of the data series $d$ and TSI, $\boldsymbol{\eta}_{0}$ is the mean of $\mathbf{y}_{t}$ and $\boldsymbol{\varepsilon}_{t}$ denotes the vector of the error terms given the information set $\Psi_{t-1} \cdot \mathbf{H}_{t}$ is the conditional variance-covariance matrix which is decomposed as follows according to Engle's (2002) Dynamic Conditional Correlation (DCC) GARCH model:

$$
\mathbf{H}_{t}=\mathbf{D}_{t} \boldsymbol{\Pi}_{t} \mathbf{D}_{t}
$$

in which $\mathbf{D}_{t}=\operatorname{diag}\left(h_{d, t}^{1 / 2}, h_{t s i, t}^{1 / 2}\right)$ is the diagonal matrix of the conditional standard deviations obtained from a univariate $\operatorname{GARCH}(1,1)$ model. The term $\boldsymbol{\Pi}_{t}$ is the conditional correlation matrix, which is computed using:

$$
\rho_{d, t s i, t}=\frac{h_{d, t s i, t}}{h_{d, t}^{1 / 2} h_{t s i, t}^{1 / 2}}
$$

where, $h_{d, t s i, t}$ is the conditional covariance between the two series and $\rho_{d, t s i, t}$ is time varying correlation coefficient that estimates the time varying relationship between inbound tourist arrivals from each source market and the term structure of interest rates.

If $\rho_{d, t s i, t}>0$ then a positive relationship between inbound tourism demand and yield curve spreads is observed. Consequently, a positive (negative) shock to inbound tourism demand is an important driver behind future economic conditions. Equally, it also implies that a shock of equal sign to future economic conditions could have a significant effect on tourist arrivals from the source markets. Whilst a negative relationship observed $\left(\rho_{d, t s i, t}<0\right)$ suggests that shocks to tourism demand and the term structure of interest rates have differential effect on each other. Conversely, should $\rho_{d, t s i, t}$ tends towards zero, this implies that there is little or no evidence of a common 
source of risk evident and as such, shocks to tourism demand has no spillover effect on future economic conditions and vice versa.

\section{Data and descriptive statistics}

\subsection{The Data}

Various measures of demand for tourism have been used in previous studies ranging from tourist arrivals, consumer spending by tourists to the number of nights spent in accommodation (Song and $\mathrm{Li}, 2008$ ) provides an extensive review of such previous studies). For the purpose of this study, this paper uses monthly data on tourists' arrivals to Spain from Germany, France, Netherlands, Italy and UK from January 1998 until June 2017, equivalent to 234 observations. The study also considers the total number of tourist arrivals from around the world, although owing to restrictions in the availability of data, the start date is January 2000. As a result, the origin countries considered in this study represents on average $68 \%$ of total arrivals to Spain. The arrivals data was provided by passport control from the Police General Direction, but supplied by the Ministerio de Industria, Energia y Turismo.

Given the nature of this study, using tourist spending as a proxy for tourism demand may be more useful than tourist arrivals to investigate the economic effects of tourism on related sectors and the wider economy (Song et al., 2010). However, problems of multicolinearity associated with the use of tourism expenditure have been identified in previous studies (Gunduz and Hatemi-J, 2005; Katircioglu, 2009). Moreover, the use of tourists' arrivals has been proven to be a useful proxy for tourism income (Antonakakis et al., 2015). Another reason for not considering the tourist expenditure variable relates to problems in collecting the data that gives rise to bias and thus poses issues on the reliability of the information set as a measure of demand (Song et al., 2010).

For the construction of our leading indicator variable, the term structure of interest rates i.e. the yield curve, the monthly benchmark yield data of the Spanish 3-month treasury bills and 10-year government bonds was downloaded from Bloomberg. It is worth noting that it is common practice in the tourism literature to obtain data from multiple sources in a study of this nature given restrictions on the availability of data (Seetaram, et al., 2016). As with previous studies, the yield curve is defined as the 10year government bonds minus 3-month treasury yields (Estrella and Hardouvelis, 1991; Estrella and Mishkin, 1998). 
Hence, an upward sloping "normal" yield curve indicates that expected economic growth prospects are positive, associated with an anticipated increase in inflation. In such a scenario, long-term bond yields rise relative to short-term yields as investors find investing in long-term debt less attractive. Conversely, an inverted yield curve suggests an anticipated decline in economic growth and a slowing of future inflation - thus reducing the appeal of short-term debt, causing investors to invest in long-term bonds. To provide some intuition, consider the relationship between short and long-term rates, where the yield is defined as:

$$
y_{t}^{n}=\frac{\left(y_{i}+y_{t=1}^{e}+\ldots \ldots+y_{t+n-1}^{e}\right)}{n}=L_{t}^{n}
$$

The term $y_{t}^{n}$ refers to the yield on a bond at maturity $n$, at time period $t$, which in turn represents the expected yield at time period $t+j$ on the basis of available information at time $t$. The $\frac{\left(y_{i}+y_{t=1}^{e}+\ldots \ldots+y_{t+n-1}^{e}\right)}{n}=L_{t}^{n} \quad$ is consistent with the Expectations Hypothesis of the Term Structure (EHTS) which postulates that the yield on a bond with a long maturity is determined by expected yields in the short term over the duration of the bond. $L_{t}^{n}$ represents the liquidity premium for an $n$ period bond at time $t$. The longer the duration of the bond, the higher $L_{t}^{n}$ becomes to compensate investors for taking on interest rate and inflation risk and as such, implies an upward sloping yield curve. On the other hand, if $L_{t}^{n}=0$ and that expected short term yields fall below actual yields with the same maturity, in such a scenario EHTS explains 100\% of the change in long yields which will result in an inverted yield curve.

To sum up, with future economic growth prospects, the yield curve is upward sloping due to the widening of the spread, whereas the reverse holds true in the event of an anticipated economic contraction in the future. A zero spread is the result of a flat yield curve, indicates that the economy is going through a transitional phase in the economic cycle from growth and an expected increase in inflation ("normal" yield curve) to a recession (associated with an inverted yield curve) or vice versa.

\subsection{Preliminary Analysis and Descriptive Statistics}

\subsubsection{Tourist arrivals and the Spanish yield curve spread}

Figure 1 plots the monthly tourist arrivals to Spain from the key origin countries, as well as, the global tourist arrivals. It is clear that the UK is the most important origin 
country for Spanish tourism, followed by France and Germany. By contrast, the Netherlands provides the lowest number of tourist arrivals, among these top five source markets. Seasonal patterns in the data is evident, as expected, between high and low seasons. Another observation in the data relates to the decline in tourist arrivals to Spain from all source countries during the GFC, which seemed to rebound from 2010 onwards.

[Please Insert Figure 1 here]

To capture the distinctive characteristics in the tourist arrivals data and to remove the seasonal patterns, the twelfth month (year-on-year) difference in the logarithms of the series is computed, in the same manner as Bartolome et al. (2009). Figure 2, which plots the transformed series, confirms the removal of seasonal patterns observed previously and it shows that tourist arrivals appear to be stationary. It is noteworthy to mention that tourist arrivals exhibits high levels of volatility throughout our sample period, with the GFC exhibiting a decline in tourist arrivals from all source markets, as also shown in Figure 1. In addition, Figure 2 clearly shows the decline in Italian tourist arrivals in 2011-2012, which is related to the rise in economic insecurity due to the recession experienced in Italy (D’Ambrosio and Rohde 2014). Interestingly, global tourism demand to Spain is least volatile, whereas arrivals from Italy and the Netherlands exhibits the greatest source of volatility throughout the sample.

[Please Insert Figure 2 here]

For the sake of consistency, the twelfth month difference in the term structure of interest rates is also computed to ensure stationarity in the series. Figure 3 plots both the yield spreads (depicted by the solid line) and transformed series (dotted line) with the latter revealing the characteristics of a stationary series around the zero point. Furthermore, the figure depicts some interesting characteristics worth noting within the context of Spanish yield curve spreads and its economic performance, with the first being the decline in the yield curve spread in the early 2000s. Such a decline can be explained by the slower growth rates of the Spanish economy during this period, which triggered the bond markets to revise downwards their earlier positive expectations of the years 1998-1999.

Another notable observation is that the twelfth month difference in the Spanish yield curve spread reached its peak in 2008-2009. Whilst the upward trend is indicative of positive prospects for the Spanish economy, this is not confirmed by the GDP readings, which, according to the OECD (2018), saw a double dip recession (2008 - 2009 and 2011 - 2013). Indeed, recent evidence reported in the economics literature points to a 
disconnection observed between spreads and economic growth (De Grauwe and Ji, 2013). Based on the aforementioned study, a plausible explanation behind the surge in yield curve spreads in both periods could be attributable to negative market sentiments caused by country-specific risks (such as the effectiveness of the tax system or governance quality) as opposed to economic fundamentals. Equally, the height of the European Debt Crisis in 2009-2012 saw evidence of contagion from the downgrade of Greek debt on Eurozone countries (Arezki et al., 2011), as well as, the Spanish sovereign debt, which led to the significant increase in the yield curve spread (Afonso et al., 2012).

Finally, Figure 3 shows a continuous decline in yield curve spreads during the period 2012-17, which coincides with the intervention of the European Central Bank (ECB) initially through the implementation of the Long Term Refinancing Operation (Petmezas and Santamaria, 2014) and the start of the quantitative easing programme in March 2015 (Gambetti and Musso, 2017). Both policy interventions involving the purchase of 10-year bonds to drive down yields (Joyce et al., 2011), impacted on the ability of the term structure to act as a leading economic indicator for future economic conditions.

[Please Insert Figure 3 here]

\subsubsection{Descriptive Statistics}

Table 1 provides the descriptive statistics of the transformed series (i.e. the twelfth month difference in the logarithms of the series). On average, year-on-year increases in global tourism demand and from all source markets is reported, with the highest growth rates observed from the France followed by the Netherlands. It is also worth mentioning that tourist arrivals from Germany and Italy exhibit the greatest source of volatility, as shown by the respective coefficients of variation. By contrast, global tourist arrivals exhibit the least volatile behaviour when compared with the source markets. Finally, the term structure of interest rates (TSIR) exhibits, on average, an upward sloping pattern, thus suggesting that bond markets for the majority of the sample period appears to anticipate positive economic prospects for the Spanish economy. Nevertheless, the high standard deviation reveals that there are significant revisions to their expectations regarding the future economic prospects in Spain. In addition, the fact that the minimum value is negative indicates that a downward sloping yield curve is also evident during the sample period, which reflects expectations about an economic downturn. 
Evidence of skewness and leptokurtosis in all data series is also evident along with high Jarque-Bera test statistics for normality. In all cases, the null hypothesis that each series is normally distributed is overwhelmingly rejected at the 0.01 level of significance. Based on Ljung-Box $Q(10)$ and $Q^{2}(10)$ statistics, the high values reported is indicative of serial correlation and conditional heteroskedascity in the data, which combined with evidence of leptokurtosis, justifies the use of the DCC-GARCH model in this study.

[Please Insert Table 1 here]

Table 1 also provides a preliminary analysis on the unconditional correlation coefficients between the transformed series of the tourism demand (from all source markets) and the TSIR. Two interesting observations arise from the correlation matrix. Firstly, the positive correlation estimates between all tourism demand series, hence tourist arrivals from different countries exhibit common movements (this was also evident in Figures 1 and 2, as well). More importantly, though, a negative relationship between inbound tourism demand and Spanish yield curve spreads is evident over the sample period. In other words, an increase (decrease) in tourism demand is associated with a decline (increase) in yield curve spreads and vice versa. These preliminary findings are rather surprising compared with the initial expectations on Section 2.1. Should tourist arrivals have a positive impact in the Spanish economy, as suggested by the tourism-led economic growth hypothesis, then a positive relationship should be evident, on average. Similar arguments hold even in the case that the conversion hypothesis holds, which suggests that the economic conditions affect tourism demand in a destination country. Thus, if expected economic conditions, as these expressed by the term structure of interest rates, influence tourism demand, then again one would expect a positive unconditional correlation estimate.

The negative unconditional correlation estimates raise a number of important inferences. For instance, increased tourism demand may not be a sufficiently important driver to reverse bond markets' expectation for worse economic conditions (downward sloping yield curve); hence, it is argued that tourism might not be related to economic performance. Equally though, assuming that expected economic growth prospects are positive (as depicted by an upward sloping yield curve), tourists may perceive the destination as becoming more expensive, which could cause a decline in tourism demand. 
Yet, it is noteworthy to mention that this is a preliminary analysis with static correlation estimates, which as previous studies report (Seo et al., 2009), does not capture the full dynamics of the tourism- expected economic growth relationship.

\subsubsection{Unit Root Tests}

Confirmation that the transformed series is stationary represents a first step before proceeding with the empirical analysis. The problems associated with using traditional approaches from Dickey and Fuller $(1979,1981)$ as well as Phillips and Perron (PP) (1988) relate to the appropriate selection of lags and low power of the ADF test (Cook, 2001) and poor size issues of the PP method should the MA term be negative and large in magnitude (Schwert, 1989). Additionally, the low power associated with the ADF test increases the likelihood of accepting the null hypothesis of a unit root when the series is stationary, particularly when the parameter in the autoregressive component is close to one (Caner and Killian, 2001). In view of these shortcomings, the Ng-Perron (2001) Mtest for a unit root on tourist arrivals and Spanish yield curve spreads is proposed. To increase the power of the unit root test, this approach uses Generalised Leased Squares (GLS) to de-trend the data and Modified Information Criterion (MIC) to select the optimal number of lags. Table 2 reports the $\mathrm{Ng}$-Perron test results, represented by four statistics (MZa, MZt, MSB and MPT) on all series used in this study.

[Please Insert Table 2 here]

Applying the Ng-Perron test on the twelfth month difference in tourist arrivals and yield curve spreads reveals that the null hypothesis of a unit root is overwhelmingly rejected. As a result, the transformed series are stationary.

\section{Empirical results}

\subsection{DCC-GARCH Model Estimates}

The first step to estimating the time varying correlation of inbound tourism demand and the term structure of interest rates requires estimating the DCC-GARCH model of equations 1 and 2. Table 3 presents the model coefficient estimates using the BHHH algorithm. The results provide a number of preliminary observations. First, GARCH effects are evident on all tourist demand variables and the Spanish yield curve spreads. Secondly, the impact of shocks to tourist arrivals on the persistence of long-term volatility (as measured by the sum of $a_{1}+b_{1}$ ) is most profound for tourist arrivals from France followed by the Netherlands. Interestingly for the Spanish term structure, long- 
term volatility persistence, and hence the degree to which financial markets revise their expectations of future economic conditions, are sensitive to shocks to the shape of the yield curve. These shocks to the TSIR are sourced by the arrival of macroeconomic news that causes a revision of interest rate expectations and a reappraisal of the risks associated with those expectations (see, inter alia, Pasquariello and Vega, 2007; Beber and Brandt, 2009).

[Please Insert Table 3 here]

Next, the DCC-GARCH model results are shown in Table 4, using dummy variables to control for the impact of random geopolitical and economic events reported by previous studies (Seo et al., 2009; Smeral, 2010; Song and Lin, 2010; Ritchie et al. 2010) on tourism demand. For this study three important political and economic events are chosen: namely the 9/11 terrorist attacks (2001-2002, as suggested by Garın-Munoz and Montero-Martin, 2007); the Global Financial Crisis (GFC) and subsequent European debt crisis (2007-2012) and lastly, the ECB's quantitative easing programme (20152017). To control for the GFC, a dummy variable is constructed in the similar manner to Petmezas and Santamaria (2014) to cover the 2008 banking and European Debt Crisis. To capture the effect of quantitative easing (QE), its inclusion as a control variable is motivated by studies that report a decline in long term yields when central banks purchase long term bonds (Greenwood and Vayanos, 2014). The dummy variables take the value 1 during the event and zero otherwise. To investigate the effects of these events, the first two dummies (i.e., the 9/11 attacks and GFC) are only included in the mean equation for the tourism demand of the DCC-GARCH model. Conversely, all control variables enter the mean equation of the term structure of interest rates.

The results presented in Table 4 reveal that the 2001 terrorist attack has a limited, but differential, effect on tourism demand. For instance, a statistically significant and negative effect is reported for global tourism demand and arrivals from Germany - a finding that is consistent with the results of Garın-Munoz and Montero-Martin (2007). In addition, the GFC reportedly has a significant negative effect on tourist arrivals, as expected. Turning to the TSIR, yield curve spreads increased during the terrorist attacks, a finding is that also observed during the GFC period and the ECB interventions. The statistically significant and positive effects are possibly attributable to the continuous reduction in short-run interest rates set by the ECB.

[Please Insert Table 4 here] 
Additionally, when compared with Table 3, the terrorist attacks and GFC reduced volatility persistence caused by tourism demand shocks for global arrivals and the source markets of Germany, France and Netherlands as suggested by the sum of $a_{1}+b_{1}$. Tourism demand from the UK and France are less sensitive to shocks, whereas both major events has made the source markets of Italy and in particular Germany, more responsive to demand shocks. Finally, controlling for the effects of the aforementioned events, whilst magnifying the effects of shocks to yield curve spreads, has not increased volatility persistence in the term structure of interest rates.

\subsection{Dynamic Conditional Correlation Estimates}

Using the standardised residuals generated from the $\operatorname{GARCH}(1,1)$ model estimates of Tables $3-4$, Figure 4 plots the conditional correlations between Spain's term structure of interest rates and tourist arrivals (dotted line), along with the aforementioned relationship (solid lines) adjusted by the control variables for the three events.

\section{[Please Insert Figure 4 here]}

Figure 4 reveals a number of interesting regularities. Starting with the dotted line, the volatile nature of this relationship is observed, which fluctuates both in magnitude and sign. This finding is contrary to the negative unconditional correlations observed in Table 1, which strengthens the fact that a time-varying approach is more appropriate rather than static frameworks. Even more, the evidence do not show any notable differences in the behaviour of the correlations among different origin countries. The only exception concerns time-varying correlations with tourism demand from Germany, which fluctuates mainly around -0.1 to -0.4 over the sample period. Another notable exception is the case of the UK. In particular, a shift in the behaviour of the UK tourist arrivals correlation with the Spanish yield spreads in the post-2008 period is observed. More specifically, in the pre-2008 period, time varying correlations fluctuates between 0.4 and 0.4 , whereas in the post-2008 the correlation trend is constantly negative, only to reverse back to a positive reading in 2016 .

Overall, these findings are rather surprising given that higher (narrower) the yield curve spreads are, the more optimistic (pessimistic) the future economic growth and inflationary prospects of the country. Hence, as aforementioned in Section 2.1, one would expect higher (narrower) yield spreads be accompanied by higher (lower) tourist arrivals. Similarly, higher tourist arrivals would result in better expectations for the Spanish 
economy and as such, be reflected in higher yield spreads. In short, a constant positive correlation would be expected.

Interestingly, positive time varying correlations is generally evident during the periods 2002-2003, 2007-2008 and 2012-2013. The period 2002-2003 is characterised by a rebound in the Spanish economy's growth rates (reflected by the upward sloping of the yield curve spread) and the constant increase in tourist arrivals from almost all source countries. Furthermore, for the 2007-2008 period, the decline in tourist arrivals associated with a narrowing of spreads and a flat yield curve, does coincide with the Spanish economy in transition towards a negative outlook due to the GFC and the property market collapse. Finally, during the 2012-2013 period, Spain experienced a decline in the growth rates of tourist arrivals coupled with the decline in yield spreads.

By contrast, negative correlations are evident over a longer time-period in 20032006, 2008-2012 and 2014-2017. It is rather important to highlight that the first and latter periods are characterised by positive prospects of the Spanish economy, whereas the period 2008-2012 represents the core years of the Spanish economic crisis.

Finding evidence that tourism-economic growth relationship is time varying both in sign and magnitude suggests that future economic prospects of Spain (based on yield curve spreads) and tourism demand growth are interdependent. By contrast, the findings cannot support the neutrality hypothesis (Katircioglou, 2009; Tang and Jang, 2009; Tugcu, 2014), since the correlation coefficients do not converge towards zero for long periods. In other words, the notion that tourists do not consider future economic conditions in their choice of tourism destination is not valid in relation to Spain.

Based on the aforementioned finding some rather interesting and new insights on the tourism-growth relationship can be reported. More specifically, positive correlations are evident only when a shift (either positive or negative) in the Spanish economy is anticipated. Hence, these regime changes seem to have an impact on the aforementioned relationship, thus lending support to the economic driven tourism growth hypothesis. The intuition behind this argument is that an expected change in the economic cycle provides news to tourists of an impending revival (deterioration) in the Spanish economy, which in turn, has a psychological impact on tourism demand. According the psychology literature on tourism, the decision making of the tourist in terms of the destination country of choice depends on the nature of the problem - in this instance, how to interpret the news of impeding change in future economic conditions in the destination country. According to Goldstein (2011), some tourists may be rational and take a logical approach 
to decision making based on facts whereas others will take an emotional path with an element of bias.

By contrast, negative correlations in the tourism-growth relationship suggests that tourists (especially from Germany but also from the UK) are more (less) willing to travel to Spain when its economic prospects are expected to deteriorate (improve). The intuition here is that the expectation of worse (improved) economic conditions are accompanied by cheaper (more expensive) tourism offering. Equally though, these results also indicate that positive changes in tourist arrivals is not enough to force bond markets to reverse their expectations of the Spanish economy. This represents a key finding, given that tourism demand is not an adequate driver of economic prospects in the destination country.

\subsection{Geopolitical and Economic Events and the Tourism-Expected Growth Relationship}

Finally, Figure 4 illustrates the impact of the three main geopolitical and economic events on time-varying correlations. Controlling for the said events generates correlation estimates depicted by the solid lines, whereas the grey cluster bar readings measures its impact. In other words, the latter shows the difference in sign and magnitude between the dotted and solid lines. Specifically, when the dotted line is higher (lower), in absolute terms, compared to the solid line then the specific event strengthens (weakens) the tourism-expected growth relationship. Hence, positive and negative bar readings are indicative of a change in the magnitude and sign of the aforementioned relationship.

The results in Figure 4 uncovers some unique insights into the tourism-growth relationship in the event of geopolitical and economic events. For instance, the impact of the said events on the tourism-expected growth relationship for Spain is country-specific in terms of sign and magnitude, although not throughout the study period; a finding that is in spirit with the temporal asymmetric effect of crises on tourism demand (Papatheodorou et al., 2010 and; Song \& Shanshan, 2010 amongst others). More specifically, in the vast majority of cases, the three events have served to strengthen the degree of interdependence between tourism and economic prospects based on the difference between the dotted and solid lines. These findings are robust with the exception of arrivals from Germany. Another interesting insight of the results is that 
according to the bar readings, the terrorist attacks in the US has the greatest impact on the tourism-growth relationship followed by the GFC.

According to Figure 4, the country-specific effects of the said events is best illustrated by the $9 / 11$ terrorist attacks in the US. Specifically, the time-varying negative relationship between tourist arrivals from Germany and UK with the TSIR becomes either positive (solid line) or independent of each other when the effect of the aforementioned event is removed by the control variable. Thus, despite the positive economic prospects of the period for the Spanish economy (i.e., an upward sloping yield curve), tourist arrivals from these two countries declined. A similar finding is reported for global demand. One would expect these findings given that the said events had a dramatic impact on the travel industry, regardless the performance of any economy (Perles-Ribes et al, 2016). Interestingly enough, the evidence cannot report similar behaviour from other origin countries (France, Italy and Netherlands), where the terrorist attacks in the US seem to have strengthened the positive relationship between tourism demand and Spanish economic prospects.

Additionally, the impact of the GFC is also country-specific, causing negative correlations to either strengthen or weaken, depending on the origin country. These results reflect the severity of the GFC on the national economies of different origin countries that differ across source markets due to overvalued assets and current account deficits (Claessens, et al., 2010). Added to this, the fact that negative correlation is stronger and lasts longer in duration during the GFC for the UK and France adds strength to our claim since these two countries experienced the immediate impact at the start of the crisis (Bozio et al., 2015). The magnitude and duration associated with the transmitting effects of the GFC is also reflected in the negative bar readings.

Finally, turning to impact of QE, there is some evidence that it strengthens the relationship (both positive and negative) between tourism demand and the Spanish term structure. Based on the bar readings, the results reveal that the persisting effect of QE is greatest on the aforementioned relationship that involve arrivals from the UK and France. Once again, this finding is repeated for global demand. One plausible explanation behind these findings is that QE encouraged banks to exchange bonds for loans (Tischer, 2018) which facilitated foreign demand for Spanish property (foreign buyers of property is counted as inbound tourism demand) at a time of Euro weakness. 


\section{Concluding remarks}

The aim of this study is to shift the focus of the tourism economics literature towards the dynamic relationship between tourism growth and expected (rather than current) macroeconomic conditions. Hence, in this paper the focus is on the dynamic relationship between tourist arrivals and a key economic leading indicator (i.e. the term structure of interest rates), rather than current levels of GDP. It is opine that using an economic leading indicator can reveal new insights on the tourism-economic growth relationship. The study focuses on the Spanish economy and tourism sector given that Spain is among the top ten (10) destination countries globally in terms of the tourism contribution to its economy (WTTC, 2017).

To do so, a DCC-GARCH model is employed, using monthly data on tourist arrivals to Spain from five major origin countries (Germany, France, Netherlands, Italy and UK), as well as, from around the world. The period of the study spans from January 1998 until June 2017.

The results show that the relationship between the tourist arrivals in Spain and its anticipated economic prospects in the destination country are time varying in both sign and magnitude. Interestingly enough, heterogeneity in this time-varying relationship among the different origin countries cannot be reported. The only exception being German tourist arrivals, which exhibit a constant negative correlation with the Spanish term structure of interest rates. The most important conclusion, though, which is reported for the first time, is that correlations are positive when there is a regime shift in the Spanish economy (either entering into a recession or boom phase), whereas negative correlations are observed when the Spanish economy is at a seemingly permanent state (i.e. in recession or in growth). Such findings suggest that the regime change of the economy seems to influence the behaviour of tourist arrivals. Equally though, when an economy is perceived to be at a more permanent state (either at the upper or lower side of the economic cycle), then the behaviour of tourist arrivals does not seem to be affected by the economic conditions of the country. Finally, it is shown that geopolitical and economic events, such as, the 9/11 terrorist attack, the recent GFC and the QE programme of the ECB, affect the nature of the said relationship both in sign and magnitude.

The results presented in this paper have a number of implications for strategic policy, particularly for future National Tourism Plans. For instance, given that the source markets contribute about $68 \%$ of total arrivals and the volatile nature of tourism-expected economic growth relationships, policy makers should consider investing in alternative 
source markets in promoting the brand. The sensitivity of tourism demand shocks reported using the GARCH models add weight to the importance of diversifying the risk in Spain's tourism portfolio by focusing on other markets, which National Tourism Plans should consider. This is particularly important in periods of positive correlation between tourism demand and anticipated economic developments, as well as, in the presence of geopolitical and economic shocks when fluctuations in tourism demand may be sufficient to alter future economic prospects.

Additionally, the impact of the 2001 attacks and recent GFC on the aforementioned relationship have demonstrated the need to factor in resilience into strategic decision making, particularly at a micro level. For instance, financial crises tend to alter consumer behaviour thus leading to changes in business models and the tourism offering in response (Papatheodorou et al., 2010). The strengthening in the interdependency between tourism demand and future economic growth prospects in Spain due to the transmitting effects of the 9/11 attacks and recent crisis adds weight to this argument.

Equally, by uncovering evidence that tourism demand and the Spanish term structure of interest rates are interdependent, this study provides unique insights into the importance of forecasting both tourist arrivals and GDP in policy formation. For instance, the prospect that economic growth prospects influence tourist arrivals due to the anticipated pricing of the tourism offering encourages policy makers to target investment into the brand other than the price. In doing so, policy makers could develop a greater degree of customer brand loyalty and facilitate the "word of mouth" effect (Garin-Munoz and Montero-Martin, 2007; Gounopoulos et al., 2012). Finally, the findings open the possibility of using the term structure of interest rates as information for national government to target assistance to tourism related industries particularly when a regime shift in the Spanish economy is observed.

Given that our study has focused on Spain, future studies should replicate these results for other major tourism destination countries. Another interesting avenue of further study could be the examination of the aforementioned relationship using alternative economic leading indicators so to provide additional insights. The identification of specific channels by which tourist arrivals might be an influential driver of expected economic conditions (and vice versa) is a promising area of further research. Finally, the examination of the impact of the source countries' economic conditions on outbound tourism and how this is linked to specific destinations is also important. 


\section{References}

Afonso, A., Furceri, D. \& Gomes, P. (2012). Sovereign credit ratings and financial markets linkages: Application to European data. Journal of International Money and Finance, 31(3), 606-638.

Alizadeh, A. H., \& Gabrielsen, A. (2013). Dynamics of credit spreads moments of European corporate bond indexes. Journal of Banking and Finance, 37(8), 31253144.

Antonakakis, N., Dragouni, M., \& Filis, G. (2015). Tourism and growth: The times they are a-changing. Annals of Tourism Research, 50, 165-169.

Antonakakis, N., Dragouni, M., Eeckels, B., \& Filis, G. (2017). The Tourism and economic growth enigma: examining an ambiguous relationship through multiple prisms. Journal of Travel Research, 58(1), 3-24.

Arezki, R., Candelon, B., \& Sy, A. N. R. (2011). Sovereign rating news and financial markets spillovers: Evidence from the European Debt Crisis. IMF Working Papers 11/68.

Aslan, A. (2014). Tourism development and economic growth in the Mediterranean countries: Evidence from panel Granger causality tests. Current issues in Tourism, 17(4), 363-372.

Bartolomé, A., McAleer, M., Ramos, V., \& Rey-Maquieira, J. (2009). A risk map of international tourist regions in Spain. Mathematics and Computers in Simulation, 79(9), 2741-2758.

Beber, A. \& Brandt, M.W. (2009). Resolving macroeconomic uncertainty in stock and bond markets. Review of Finance, 13, 1-45.

Bozio, A., Emmerson, C., Peichl, A., \& Tetlow, G. (2015). European Public Finances and the Great Recessiion: France, Germany, Ireland, Italy, Spain and the United Kingdom Compared. Fiscal Studies, 36(4), 405-430.

Caner, M., \& Kilian, L. (2001). Size distortions of tests of the null hypothesis of stationarity: evidence and implications for the PPP debate. Journal of International Money and Finance, 20, 639-657.

Cárdenas-García, P. J., Sánchez-Rivero, M., \& Pulido-Fernández, J. I. (2015). Does tourism growth influence economic development?. Journal of Travel Research, 54(2), 206-221.

Chan, F., Lim, C., \& McAleer, M. (2005). Modelling multivariate international tourism demand and volatility. Tourism Management, 26(3), 459-471. 
Chatziantoniou, I., Degiannakis, S., Eeckels, B., \& Filis, G. (2016). Forecasting tourist arrivals using origin country macroeconomics. Applied Economics, 48(27), 25712585

Chen, C. F., \& Chiou-Wei, S. Z. (2009). Tourism expansion, tourism uncertainty and economic growth: New evidence from Taiwan and Korea. Tourism Management, $30(6), 812-818$

Christiansen, C. (2013). Predicting severe simultaneous recessions using yield spreads as leading indicators. Journal of International Money and Finance, 32, 1032-1043.

Claessens, S., Dell"Ariccia, G., Igan, D., \& Laeven, L. (2010). Cross-country experiences and policy implications from the Global Financial Crisis. Economic Policy, 25(62), 267-293.

Cook, S. (2001). Finite-sample critical values of the Augmented Dickey-Fuller statistic: a note on lag order. Economic Issues, 6, Part 2, 31 - 38.

D'Ambrosio, C., \& Rohde, N. (2014). The distribution of economic insecurity: Italy and the U.S. over the great recession. Review of Income and Wealth, 60, S33-S52.

De Grauwe, P., Ji, Y. (2013). Self-fulfilling crises in the eurozone: an empirical test. Journal of International Money and Finance, 34, 15-36.

de Oliveira Santos, G. E. (2009). Research Note: Forecasting Tourism Demand by Disaggregated Time Series-Empirical Evidence from Spain. Tourism Economics, $15(2), 467-472$.

Dickey, D.A., \& Fuller, W.A. (1979). Distribution of the estimators for autoregressive time series with a unit root. Journal of American Statistical Association, 74, 427431.

Dickey, D.A., \& Fuller, W.A. (1981). Likelihood ratio statistics for autoregressive time series with a unit root. Econometrica, 49, 1057-1072.

Dogru, T., \& Bulut, U. (2018). Is tourism an engine for economic recovery? Theory and empirical evidence. Tourism Management, 67, 425-434.

Dogru, T., \& Sirakaya-Turk, E. (2017). Engines of tourism's growth: An examination of efficacy of shift-share regression analysis in South Carolina. Tourism Management, $58,205-214$.

Dragouni, M., Filis, G., Gavriilidis, K., \& Santamaria, D. (2016). Sentiment, mood and outbound tourism demand. Annals of Tourism Research, 60, 80-96. 
Engle, R. (2002). Dynamic conditional correlation: A simple class of multivariate generalized autoregressive conditional heteroskedasticity models. Journal of Business \& Economic Statistics, 20(3), 339-350.

Estrella, A., \& Hardouvelis, G. A. (1991). The term structure as a predictor of real economic activity. The Journal of Finance, 46(2), 555-576.

Estrella, A., \& Mishkin, F. S. (1998). Predicting US recessions: Financial variables as leading indicators. Review of Economics and Statistics, 80(1), 45-61.

Gambetti, L., \& Musso, A. (2017). The macroeconomic impact of the ECB's expanded asset purchase programme (APP). European Central Bank Working Paper Series, No 2075 .

Garin-Munoz, T., \& Montero-Martín, L. F. (2007). Tourism in the Balearic Islands: A dynamic model for international demand using panel data. Tourism Management, 28(5), 1224-1235.

Goldstein, E. B. (2011). Cognitive psychology (Third edition). Belmont, CA: Wadsworth.

Gounopoulos, D., Petmezas, D., \& Santamaria, D. (2012). Forecasting tourist arrivals in Greece and the impact of macroeconomic shocks from the countries of tourists' origin. Annals of Tourism Research, 39(2), 641-666.

Greenwood, R., \& Vayanos, D. (2014). Bond supply and excess bond returns. Review of Financial Studies, 27(3), $663\{713$.

Gunduz, L., \& Hatemi-J, A. (2005). Is the tourism-led growth hypothesis valid for Turkey?. Applied Economics Letters, 12(8), 499-504.

Hamilton, J. D., \& Kim, D. H. (2002). A reexamination of the predictability of economic activity using the yield spread. Journal of Money, Credit and Banking, 34(2), 340360 .

Harvey, C. R. (1988). The real term structure and consumption growth. Journal of Financial Economics, 22(2), 305-333.

Hibbert, M., Pavlova, I., Barber, J., \& Dandapani, K. (2011). Credit spread changes and equity volatility: Evidence from daily data. Financial Review, 46(3), 357-383.

Ivanov, S., \& Webster, C. (2013). Tourism's impact on growth: the role of globalisation. Annals of Tourism Research, 41, 231-236.

Joyce, M.A.S., Lasaosa, A., Stevens, I., \& Tong, M. (2011). The financial market impact of quantitative easing in the United Kingdom. International Journal of Central Banking, 7, 113-161. 
Katircioglu, S. T. (2009). Revisiting the tourism-led-growth hypothesis for Turkey using the bounds test and Johansen approach for cointegration. Tourism Management, 30(1), 17-20.

Lean, H. H., \& Tang, C. F. (2010). Is the tourism-led growth hypothesis stable for Malaysia? A note. International Journal of Tourism Research, 12(4), 375-378.

Lee, C., Moon, S., \& Mjelde, J.W. (2010). Disentangling the effects on the Korean economy of the $9 / 11$ terrorist attacks from the short-run effects of hosting the 2002 World Cup, using the CGE model. Tourism Economics, 16(3), 611-628.

Li, S., Blake, A., \& Cooper, C. (2011). Modelling the economic impact of international tourism on the Chinese economy: A CGE analysis of the Beijing 2008 Olympics. Tourism Economics, 17(2), 279-303.

Lorde, T., \& Moore, W. (2008a). Co-movement in tourist arrivals in the Caribbean. Tourism Economics, 14(3), 631-643.

Lorde, T., \& Moore, W. (2008b). Modeling and forecasting the volatility of long-stay tourist arrivals. Tourism Analysis, 13(1), 43-51.

Ng, S., \& Perron, P. (2001). Lag length selection and the construction of unit root tests with good size and power. Econometrica, 69(6), 1519-1554.

OECD (2018). Economic Outlook, No. 104, November 2018.

Papatheodorou, A., Roselló, J., \& Honggen, X. (2010). Global economic crisis and tourism: consequences and perspectives. Journal of Travel Research, 49(1), 39 45.

Parrilla, J. C., Font, A. R., \& Nadal, J. R. (2007). Tourism and long-term growth a Spanish perspective. Annals of Tourism Research, 34(3), 709-726.

Pasquariello, P. \& Vega, C. (2007). Informed and strategic order flow in the bond markets. Review of Financial Studies, 20, 1975-2019.

Perles-Ribes, J. F., Ramon-Rodriguez, A. B., Sevilla-Jimenez, M., \& Rubia, A. (2016).

The effects of economic crises on tourism success: an integrated model. Tourism Economics, 22(2), $417-447$.

Perles-Ribes, J. F., Ramón-Rodríguez, A. B., Rubia, A., \& Moreno-Izquierdo, L. (2017).

Is the tourism-led growth hypothesis valid after the global economic and financial crisis? The case of Spain 1957-2014. Tourism Management, 61, 96-109.

Petmezas, D., \& Santamaria, D. (2014). Investor induced contagion during the Banking and European Sovereign Debt Crisis of 2007-2012: Wealth effect or portfolio rebalancing? Journal of International Money and Finance, 49, 401-424. 
Phillips, P.C.B., \& Perron, P. (1988). Testing for a unit root in time series regression, Biometrika, 75, 335-346.

Ritchie, J. B., Amaya Molinar, C. M., \& Frechtling, D. C. (2010). Impacts of the world recession and economic crisis on tourism: North America. Journal of Travel Research, 49(1), 5-15.

Rudebusch, G. D., \& Williams, J. C. (2009). Forecasting recessions: the puzzle of the enduring power of the yield curve. Journal of Business \& Economic Statistics, 27(4), 492-503.

Schwert, G.W. (1989). Tests for unit roots: A Monte Carlo investigation. Journal of Business and Economic Statistics, 7, 147-160.

Seetaram, N., Forsyth, P., \& Dwyer, L. (2016). Measuring price elasticities of demand for outbound tourism using competitiveness indices. Annals of Tourism Research, $56,65-79$.

Seo, J. H., Park, S. Y., \& Yu, L. (2009). The analysis of the relationships of Korean outbound tourism demand: Jeju Island and three international destinations. Tourism Management, 30, 530-543.

Shareef, R., \& McAleer, M. (2005). Modelling international tourism demand and volatility in small island tourism economies. International Journal of Tourism Research, 7, 313-333.

Shareef, R., \& McAleer, M. (2007). Modelling the uncertainty in monthly international tourist arrivals to the Maldives. Tourism Management, 28(1), 23-45.

Shareef, R., \& McAleer, M. (2008). Modelling international tourism demand and uncertainty in Maldives and Seychelles: A portfolio approach. Mathematics and Computers in Simulation, 78(2-3), 459-468.

Smeral, E. (2010). Impacts of the world recession and economic crisis on tourism: Forecasts and potential risks. Journal of Travel Research, 49(1), 31-38.

Song, H., Dwyer, L., Li, G., \& Cao, Z. 2012. Tourism economics research: A review and assessment. Annals of Tourism Research, 39(3), 1653-1682.

Song, H., \& Li, G. (2008). Tourism demand modelling and forecasting-A review of recent research. Tourism Management, 29(2), 203-220.

Song, H., \& Lin, S. (2010). Impacts of the financial and economic crisis on tourism in Asia. Journal of Travel Research, 49(1), 16-30.

Song, H., \& Shanshan, L. (2010) Impacts of the financial and economic crisis on Tourism in Asia. Journal of Travel Research, 49(1), 16 - 30. 
Song, H., Li, G., Witt, S. F., \& Fei, B. (2010). Tourism demand modelling and forecasting: how should demand be measured?. Tourism Economics, 16(1), 63-81.

Sugiyarto, G., Blake, A., \& Sinclair, M. T. (2003). Tourism and globalization: Economic impact in Indonesia. Annals of Tourism Research, 30(3), 683-701.

Tang, C. F., \& Tan, E. C. (2013). How stable is the tourism-led growth hypothesis in Malaysia? Evidence from disaggregated tourism markets. Tourism Management, $37,52-57$.

Tang, C. H. H., \& Jang, S. S. (2009). The tourism-economy causality in the United States: A sub-industry level examination. Tourism Management, 30(4), 553-558.

Tischer, J. (2018). Quantitative easing, portfolio rebalancing and credit growth: Micro evidence from Germany. Bundesbank Discussion Paper, No. 20/2018.

Tugcu, C. T. (2014). Tourism and economic growth nexus revisited: A panel causality analysis for the case of the Mediterranean Region. Tourism Management, 42, 207212.

UNWTO, 2017, Tourism Highlights 2017 Edition, United Nations World Tourism Organisation, https://www.e-unwto.org/doi/pdf/10.18111/9789284419029.

Wheelock, D. C., \& Wohar, M. E. (2009). Can the term spread predict output growth and recessions? A survey of the literature. Federal Reserve Bank of St. Louis Review, 91(5 Part 1), 419-440.

WTTC, 2017, Travel and Tourism - Global Economic Impact and Issues 2017, World Travel and Tourism Council, https://www.wttc.org//media/files/reports/economic-impact-research/2017-documents/globaleconomic-impact-and-issues-2017.pdf

WTTC, 2017b, Travel and Tourism - Economic Impact 2017 Spain, World Travel and Tourism Council, https://www.wttc.org/-/media/files/reports/economic-impactresearch/countries-2017/spain2017.pdf

WTTC, 2017c, How does travel and tourism compare to other sectors?, World Travel and Tourism Council, https://www.wttc.org/-/media/files/reports/benchmarkreports/country-reports-2017/spain.pdf 


\section{Tables}

Table 1. Descriptive statistics and unconditional correlations on the transformed series (twelfth month difference).

\begin{tabular}{|c|c|c|c|c|c|c|c|}
\hline & & & Origin C & atries & & & \\
\hline & GLOBAL & BD & FR & UK & IT & NL & TSIR \\
\hline Mean & .053 & .004 & .048 & .027 & .027 & . 044 & .038 \\
\hline St. Dev & .093 & .095 & .115 & .096 & .150 & .152 & .798 \\
\hline $\begin{array}{l}\text { Coeff. of } \\
\text { Variation }\end{array}$ & 1.755 & 23.750 & 2.396 & 3.556 & 5.556 & 3.455 & 21.000 \\
\hline Max & .440 & .265 & .456 & .359 & .543 & .751 & 3.150 \\
\hline Min & -.233 & -.390 & -.261 & -.323 & -.480 & -.449 & -1.649 \\
\hline Skew & $.894 * * *$ & $-.291 *$ & $.444 * * *$ & $-.367 * *$ & -.205 & $.444 * *$ & $1.009 * * *$ \\
\hline Prob. & {$[0.00]$} & {$[0.08]$} & [0.01] & [0.03] & {$[0.00]$} & {$[0.01]$} & {$[0.00]$} \\
\hline Kurt (ex) & $3.099 * * *$ & $1.351 * * *$ & $1.349 * * *$ & $1.702 * * *$ & $0.925^{* *}$ & $2.602 * * *$ & $2.364 * * *$ \\
\hline Prob. & {$[0.00]$} & {$[0.00]$} & {$[0.00]$} & {$[0.00]$} & {$[0.01]$} & {$[0.00]$} & {$[0.00]$} \\
\hline J-Bera & 114.72 & 19.383 & 23.369 & 30.773 & 9.172 & 67.729 & 86.585 \\
\hline Prob. & {$[0.00]$} & {$[0.00]$} & {$[0.00]$} & {$[0.00]$} & {$[0.01]$} & {$[0.00]$} & {$[0.00]$} \\
\hline L-B $Q(10)$ & 821.00 & 102.35 & 186.39 & 482.17 & 138.01 & 157.34 & 689.09 \\
\hline Prob. & {$[0.00]$} & {$[0.00]$} & {$[0.00]$} & {$[0.00]$} & {$[0.00]$} & {$[0.00]$} & {$[0.00]$} \\
\hline L-B $\left.Q^{2} 10\right)$ & 460.39 & 133.39 & 85.250 & 64.402 & 25.795 & 32.706 & 373.58 \\
\hline Prob. & {$[0.00]$} & {$[0.00]$} & {$[0.00]$} & {$[0.00]$} & {$[0.01]$} & {$[0.00]$} & {$[0.00]$} \\
\hline GLOBAL & 1.00 & & & & & & \\
\hline & -- & & & & & & \\
\hline BD & $.72 * * *$ & 1.00 & & & & & \\
\hline & {$[0.00]$} & -- & & & & & \\
\hline FR & $.51 * * *$ & $.24 * * *$ & 1.00 & & & & \\
\hline & {$[0.00]$} & {$[0.00]$} & -- & & & & \\
\hline UK & $.78 * * *$ & $.41 * * *$ & $.22 * * *$ & 1.00 & & & \\
\hline & {$[0.00]$} & [0.00] & {$[0.00]$} & -- & & & \\
\hline IT & $.43 * * *$ & $.23 * * *$ & $.30 * * *$ & $.20 * *$ & 1.00 & & \\
\hline & [0.00] & [0.00] & {$[0.00]$} & [0.01] & -- & & \\
\hline NL & $.49 * * *$ & $.21 * * *$ & $.21 * * *$ & $.45^{* * *}$ & $.23 * * *$ & 1.00 & \\
\hline & [0.00] & [0.00] & [0.00] & [0.00] & {$[0.00]$} & -- & \\
\hline TSI & $-.48 * * *$ & $-.35 * * *$ & -.09 & $-.40 * * *$ & $-.27 * * *$ & $-.27 * * *$ & 1.00 \\
\hline & {$[0.00]$} & {$[0.00]$} & {$[0.21]$} & {$[0.00]$} & {$[0.00]$} & [0.00] & -- \\
\hline $\begin{array}{l}\text { Notes: Glob } \\
\text { UK IT and } \\
\text { Netherlands. } \\
* * \text { implies si } \\
\text { serial correla }\end{array}$ & $\begin{array}{l}\text { refers to tot } \\
\text { L refers to } \\
\text { SIR refers } t \\
\text { ificance at } \\
\text { on and heter }\end{array}$ & $\begin{array}{l}\text { nbound } \\
\text { he term str } \\
1 \% \text { and } 5 \% \\
\text { xedascity }\end{array}$ & $\begin{array}{l}\text { m demand } \\
\text { ad from } \\
\text { are of inter } \\
\text { vels. L-B }\end{array}$ & $\begin{array}{l}\text { all sourc } \\
\text { any, Fran } \\
\text { ates. Stanc } \\
\text { and L-B }\end{array}$ & $\begin{array}{l}\text { markets a } \\
\text {, United } \\
\text { d errors a } \\
\text { (10) are L }\end{array}$ & $\begin{array}{l}\text { nd the wo } \\
\text { ngdom, I } \\
\text { in parenth } \\
\text { g-Box tes }\end{array}$ & $\begin{array}{l}\text { d; BD, FR, } \\
\text { ly and the } \\
\text { is. } * * * \text { and } \\
\text { tatistics for }\end{array}$ \\
\hline
\end{tabular}


Table 2: Unit root tests of the transformed series (twelfth month difference)

\begin{tabular}{|c|c|c|c|c|c|c|}
\hline \multirow[b]{2}{*}{ Transformed series } & & \multirow[b]{2}{*}{$\mathbf{L a g}^{\mathrm{a}}$} & \multicolumn{4}{|c|}{ Ng-Perron } \\
\hline & & & MZa & MZt & MSB & MPT \\
\hline GLOBAL & & 2 & -8.390 & -1.978 & .236 & 11.10 \\
\hline BD & & 2 & -12.75 & -2.496 & .196 & 2.036 \\
\hline FR & & 2 & -9.491 & -2.134 & .225 & 2.757 \\
\hline UK & & 12 & -9.821 & -2.213 & .225 & 9.293 \\
\hline IT & & 4 & -9.070 & -2.110 & .233 & 2.778 \\
\hline NL & & 2 & -19.02 & -3.083 & .162 & 1.290 \\
\hline TSIR & & 12 & -12.67 & -2.499 & .197 & 7.293 \\
\hline Asymptotic & $1 \%$ & & -13.80 & -2.580 & .174 & 1.780 \\
\hline Critical Values: ${ }^{*}$ & $5 \%$ & & -8.100 & -1.980 & .233 & 3.170 \\
\hline & $10 \%$ & & -5.700 & -1.620 & .275 & 4.450 \\
\hline
\end{tabular}


Table 3: Benchmark DCC-GARCH(1,1) model estimates

\begin{tabular}{|c|c|c|c|c|c|c|c|}
\hline \multirow[b]{2}{*}{ Coefficients } & \multicolumn{5}{|c|}{ Origin Countries } & \multirow[b]{2}{*}{ NL } & \multirow[b]{2}{*}{ TSIR } \\
\hline & TOTAL & BD & FR & UK & IT & & \\
\hline \multirow[t]{2}{*}{$\alpha_{0}$} & $.042 * * *$ & $.015 * * *$ & $.040 * * *$ & $.038 * * *$ & $.051 * * *$ & $.043 * * *$ & $-.081 * * *$ \\
\hline & $(0.004)$ & $(0.006)$ & $(0.007)$ & $(0.005)$ & $(0.010)$ & $(0.010)$ & $(0.026)$ \\
\hline \multirow[t]{2}{*}{$a_{0}$} & $.049^{+* *}$ & $.013^{+* *}$ & $.052^{+}$ & $.017^{+* * * *}$ & $.059^{+* *}$ & $.013^{+* *}$ & $.021 * * *$ \\
\hline & $(0.021)$ & $(0.006)$ & $(0.041)$ & $(0.006)$ & $(0.027)$ & $(0.007)$ & $(0.007)$ \\
\hline \multirow[t]{2}{*}{$a_{1}$} & $.217 * * *$ & $.262 * * *$ & $.133^{* *}$ & $.361 * *$ & $.261 * *$ & $.115 * * *$ & $.474 * * *$ \\
\hline & $(0.083)$ & $(0.097)$ & $(0.059)$ & $(0.144)$ & $(0.099)$ & $(0.040)$ & $(0.101)$ \\
\hline \multirow[t]{2}{*}{$b_{1}$} & $.653 * * *$ & $.602 * * *$ & $.826 * * *$ & $.402^{* *}$ & $.482 * * *$ & $.817 * * *$ & $.519 * * *$ \\
\hline & $(0.091)$ & $(0.097)$ & $(0.077)$ & $(0.161)$ & $(0.165)$ & $(0.053)$ & $(0.031)$ \\
\hline$a_{1}+b_{1}$ & .871 & .864 & .959 & .763 & .743 & .932 & .993 \\
\hline GARCH LogL & 288.26 & 224.16 & 183.22 & 256.30 & 117.46 & 123.73 & -163.42 \\
\hline \multirow[t]{2}{*}{$\alpha_{1}$} & $.273 * * *$ & $.066 * * *$ & $.201 * * *$ & $.104 * *$ & $.180 * * *$ & $.258 * * *$ & --- \\
\hline & $(0.065)$ & $(0.007)$ & $(0.071)$ & $(0.043)$ & $(0.061)$ & $(0.083)$ & \\
\hline \multirow[t]{2}{*}{$\beta_{1}$} & $.564 * * *$ & $.823 * * *$ & $.740 * * *$ & $.851 * * *$ & $.612 * * *$ & $.439 * * *$ & --- \\
\hline & $(0.113)$ & $(0.220)$ & $(0.108)$ & $(0.080)$ & $(0.153)$ & $(0.028)$ & \\
\hline DCC LogL & -522.75 & -599.01 & -590.61 & -591.66 & -589.72 & -592.82 & \\
\hline \multirow[t]{2}{*}{$Q^{2}(10)$} & 4.823 & 5.824 & 3.437 & 7.183 & 6.128 & 3.720 & 16.042 \\
\hline & {$[0.90]$} & {$[0.83]$} & {$[0.97]$} & {$[0.71]$} & {$[0.80]$} & {$[0.96]$} & {$[0.10]$} \\
\hline \multirow[t]{2}{*}{$\chi^{2}(10)$} & 4.812 & 6.174 & 3.213 & 7.808 & 5.378 & 6.132 & 17.065 \\
\hline & {$[0.90]$} & {$[0.80]$} & {$[0.98]$} & {$[0.65]$} & {$[0.86]$} & {$[0.80]$} & {$[0.07]$} \\
\hline \multirow[t]{2}{*}{$F$-Stat } & 0.465 & 0.603 & 0.309 & 0.769 & 0.523 & 0.599 & 1.760 \\
\hline & {$[0.91]$} & {$[0.81]$} & {$[0.98]$} & {$[0.66]$} & {$[0.87]$} & {$[0.81]$} & {$[0.07]$} \\
\hline
\end{tabular}

Notes: The coefficients $\boldsymbol{\alpha}_{1}$ and $\boldsymbol{\beta}_{1}$ represents the benchmark DCC model. Standard errors are in parenthesis. *** and ** represent significance at the $1 \%$ and $5 \%$ levels; the symbol ${ }^{+}$implies that the coefficient is multiplied by 100 for readability. $Q^{2}(10)$ are autocorrelation test statistics for serial correlation on the standardized residuals. $\chi^{2}(10)$ and $F$-Stat are ARCH(10) test statistics. 
Table 4: DCC-GARCH(1,1) model estimates with control variables

\begin{tabular}{|c|c|c|c|c|c|c|c|}
\hline \multirow[b]{2}{*}{ Coefficients } & \multicolumn{6}{|c|}{ Origin Countries } & \multirow[b]{2}{*}{$T S I$} \\
\hline & GLOBAL & BD & FR & UK & IT & NL & \\
\hline \multirow[t]{2}{*}{$\alpha_{0}$} & $.055 * * *$ & $.026 * * *$ & $.063 * * *$ & $.051 * * *$ & $.062 * * *$ & $.050 * * *$ & $-.228 * * *$ \\
\hline & $(0.005)$ & $(0.007)$ & $(0.011)$ & $(0.006)$ & $(0.014)$ & $(0.010)$ & $(0.040)$ \\
\hline \multirow[t]{2}{*}{$\gamma_{1}^{2001}$} & $-.033 * *$ & $-.068 * * *$ & $.161 * * *$ & -.020 & .037 & $.062 *$ & $.122 * * *$ \\
\hline & $(0.015)$ & $(0.019)$ & $(0.043)$ & $(0.026)$ & $(0.033)$ & $(0.037)$ & $(0.008)$ \\
\hline \multirow[t]{2}{*}{$\gamma_{2}{ }^{\mathrm{GFC}}$} & $-.039 * * *$ & $-.028 * *$ & -.026 & $-.039 * * *$ & $-.040 *$ & $-.058 * * *$ & $.303 * * *$ \\
\hline & $(0.009)$ & $(0.013)$ & $(0.018)$ & $(0.009)$ & $(0.022)$ & $(0.020)$ & $(0.048)$ \\
\hline \multirow[t]{2}{*}{$\gamma_{\mathbf{3}}^{\mathrm{QE}}$} & -- & -- & --- & -- & -- & -- & $.231 * * *$ \\
\hline & --- & --- & --- & --- & --- & --- & $(0.071)$ \\
\hline \multirow[t]{2}{*}{$a_{0}$} & $.089^{+* *}$ & $.017^{+*}$ & $.094^{+*}$ & $.016^{+* *}$ & $.054^{+* *}$ & $.013^{+}$ & $.037 * * *$ \\
\hline & $(0.044)$ & $(0.009)$ & $(0.055)$ & $(0.007)$ & $(0.022)$ & $(0.011)$ & $(0.006)$ \\
\hline \multirow[t]{2}{*}{$a_{1}$} & $.213 * *$ & $.351 * * *$ & $.124 * * *$ & $.327 * *$ & $.275 * * *$ & $.112 *$ & $.840 * * *$ \\
\hline & $(0.103)$ & $(0.110)$ & $(0.045)$ & $(0.151)$ & $(0.094)$ & $(0.064)$ & $(02106)$ \\
\hline \multirow[t]{2}{*}{$b_{1}$} & $.510 * * *$ & $.490 * * *$ & $.819 * * *$ & $.459 * *$ & $.484 * * *$ & $.809 * * *$ & $.155 * *$ \\
\hline & $(0.188)$ & $(0.120)$ & $(0.064)$ & $(0.176)$ & $(0.138)$ & $(0.114)$ & $(0.071)$ \\
\hline$a_{1}+b_{1}$ & .723 & .841 & .943 & .786 & .759 & .921 & .995 \\
\hline GARCH LogL & 296.40 & 222.20 & 163.60 & 251.42 & 120.36 & 145.84 & -136.46 \\
\hline \multirow[t]{2}{*}{$\alpha_{1}$} & $.241 * * *$ & $.154 * * *$ & $.120 *$ & $.152 * * *$ & $.112 *$ & $.242 * * *$ & --- \\
\hline & $(0.081)$ & $(0.009)$ & $(0.069)$ & $(0.010)$ & $(0.066)$ & $(0.072)$ & \\
\hline \multirow[t]{2}{*}{$\beta_{1}$} & $.546 * * *$ & $.656 * * *$ & $.692 * * *$ & $.689 * * *$ & $.656 * * *$ & $.463 * *$ & --- \\
\hline & $(0.163)$ & $(0.231)$ & $(0.209)$ & $(0.236)$ & $(0.208)$ & $(0.232)$ & \\
\hline DCC LogL & -530.34 & -600.28 & -601.58 & -595.75 & -590.50 & -665.51 & --- \\
\hline \multirow[t]{2}{*}{$Q^{2}(10)$} & 5.509 & 8.875 & 3.849 & 7.022 & 4.708 & 5.697 & 16.82 \\
\hline & {$[0.86]$} & {$[0.54]$} & {$[0.95]$} & {$[0.72]$} & {$[0.91]$} & {$[0.84]$} & {$[0.08]$} \\
\hline \multirow[t]{2}{*}{$\chi^{2}(10)$} & 5.264 & 8.697 & 4.261 & 6.121 & 4.193 & 6.155 & 13.53 \\
\hline & {$[0.87]$} & {$[0.56]$} & {$[0.93]$} & {$[0.81]$} & {$[0.94]$} & {$[0.80]$} & {$[0.20]$} \\
\hline \multirow[t]{2}{*}{$F$-Stat } & 0.510 & 0.860 & 0.412 & 0.598 & 0.406 & 0.601 & 1.370 \\
\hline & {$[0.88]$} & {$[0.57]$} & {$[0.94]$} & {$[0.81]$} & [0.94] & {$[0.81]$} & {$[0.20]$} \\
\hline
\end{tabular}




\section{Figures}

Figure 1: Monthly international tourist arrivals to Spain
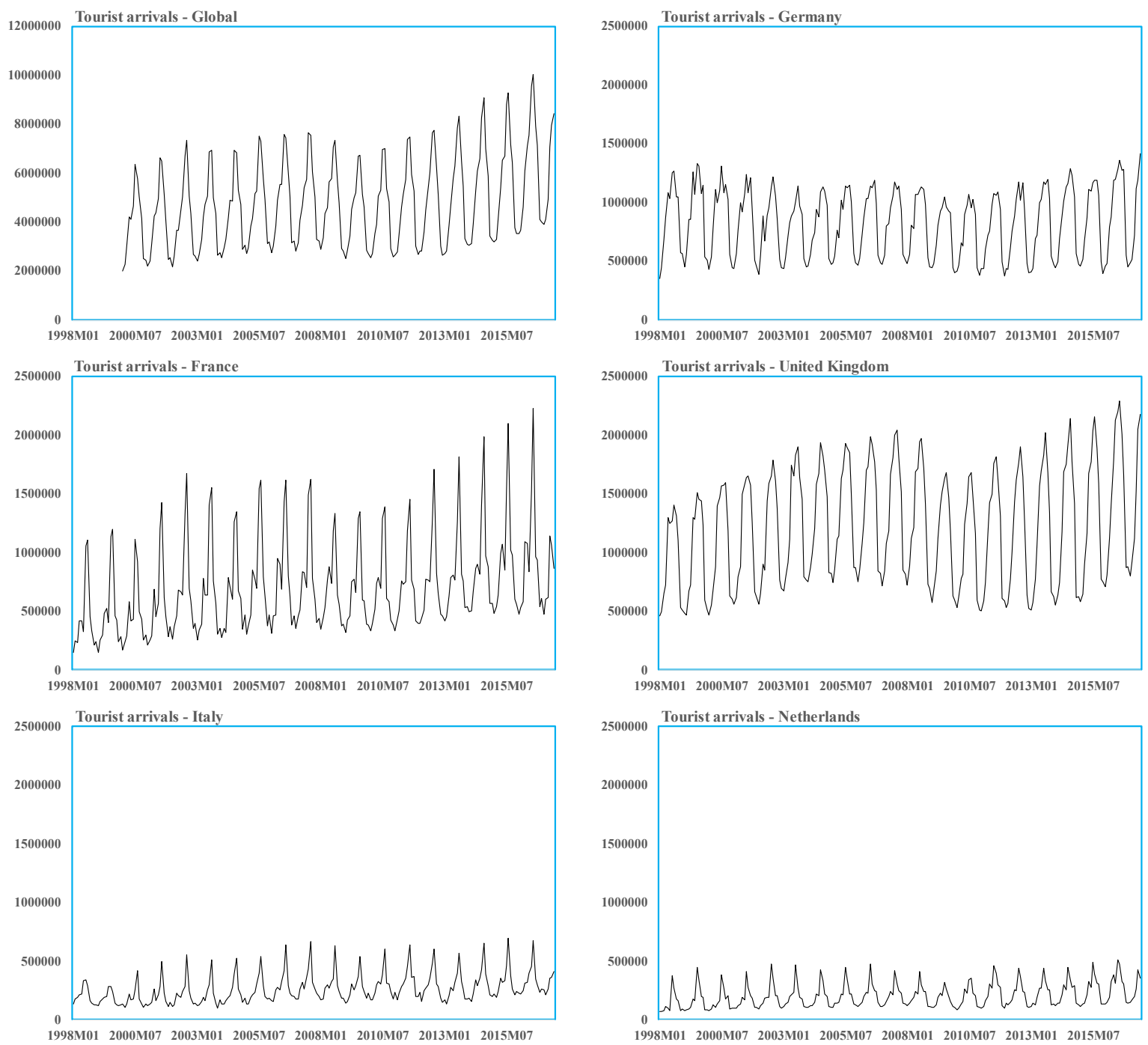
Figure 2: Twelfth month difference in tourist arrivals
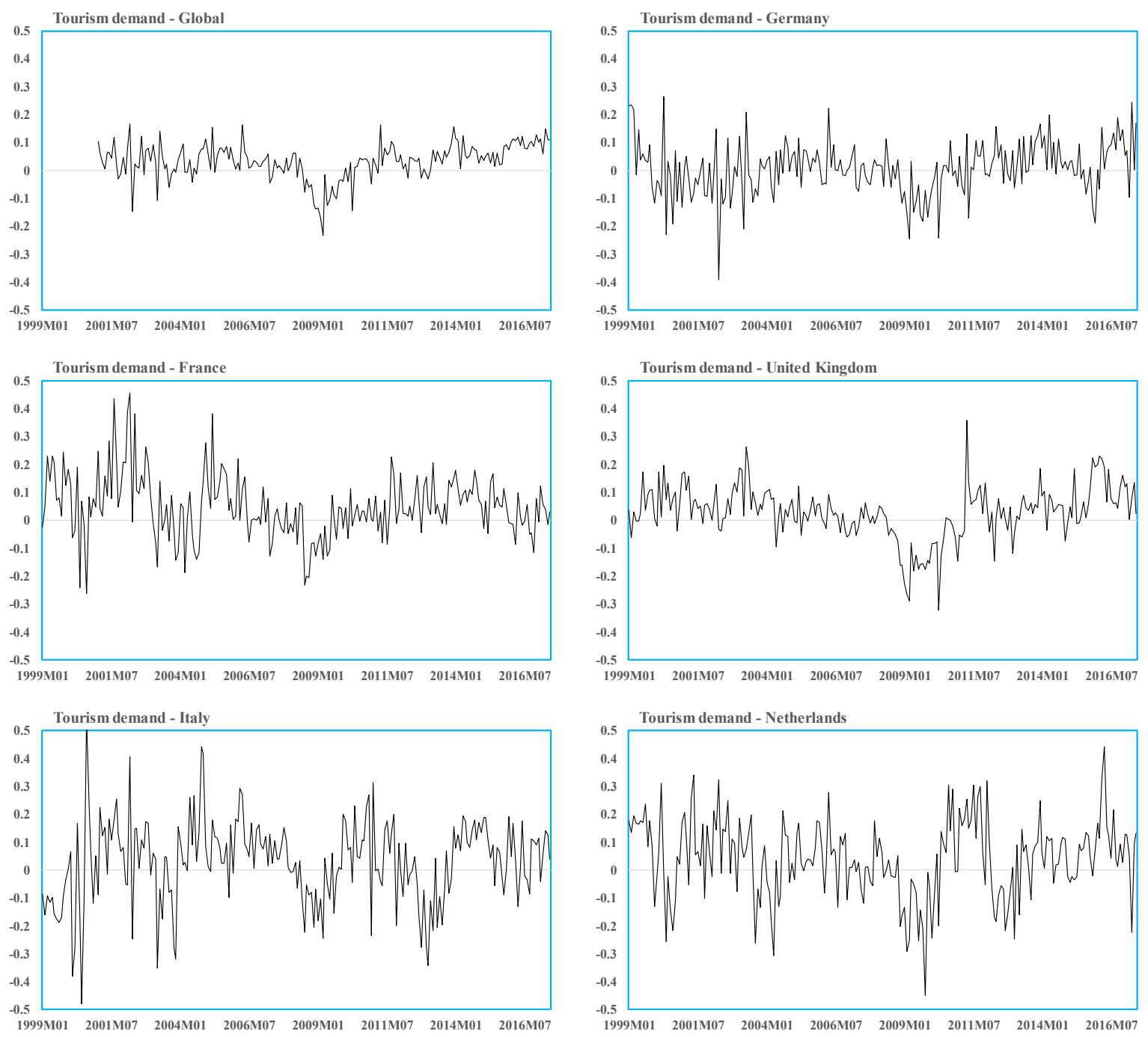
Figure 3: Spanish yield spread levels versus twelfth month difference

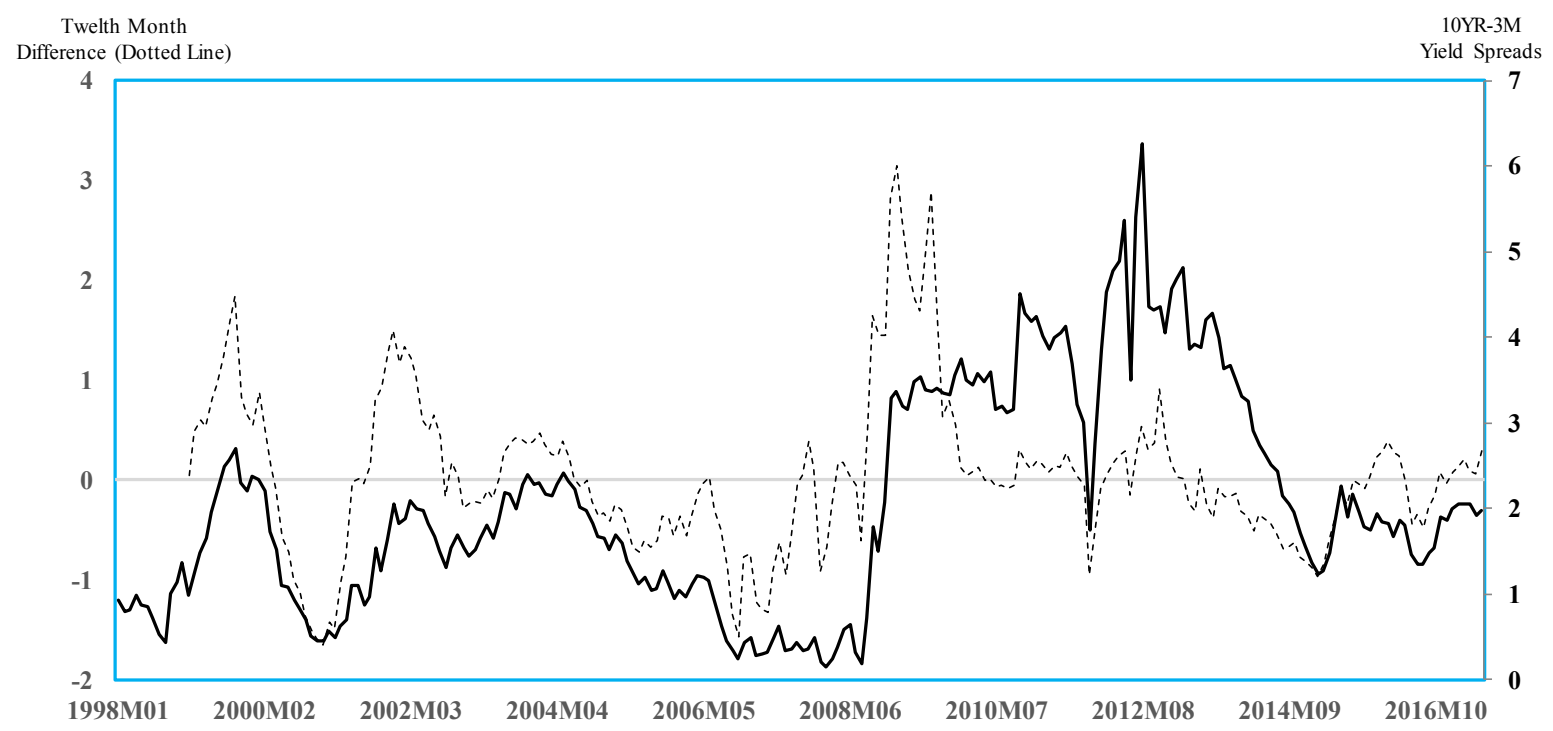


Figure 4: Dynamic Conditional Correlations - the impact of economic and political events

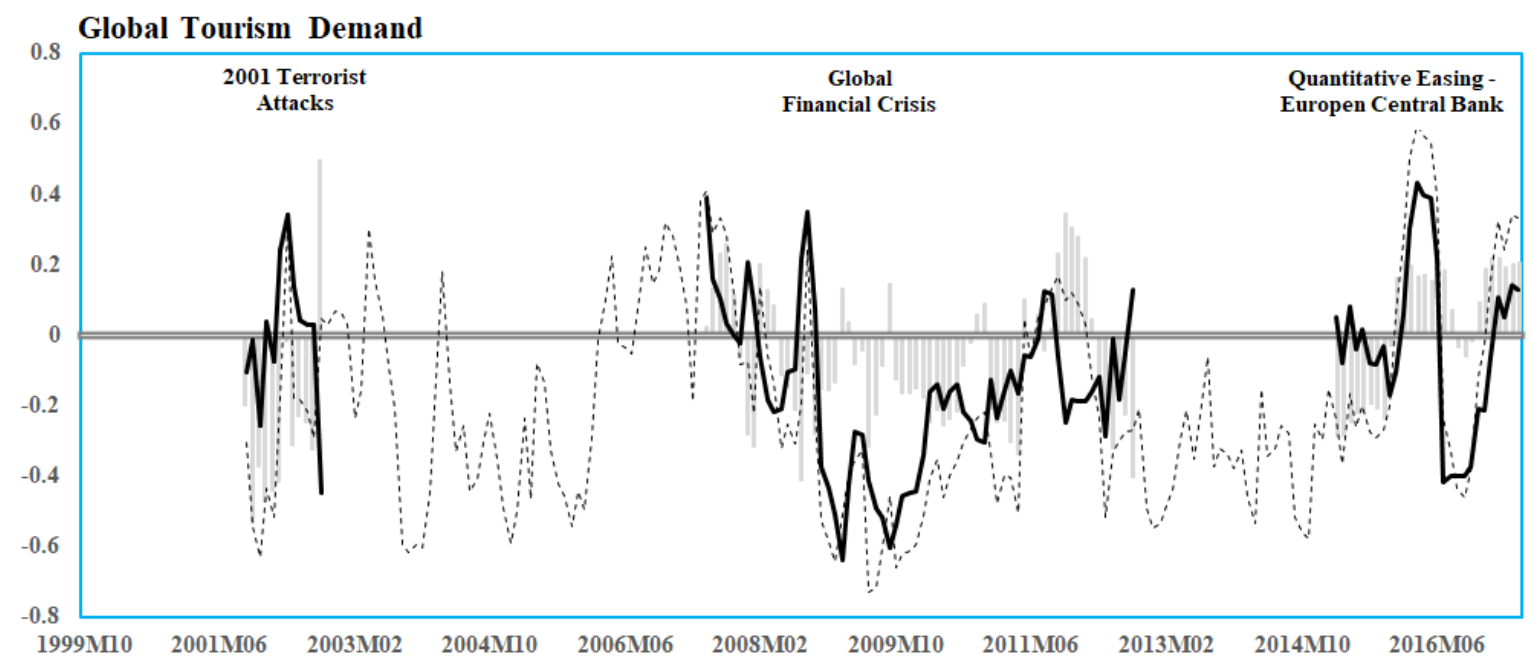

Tourism Demand - Germany

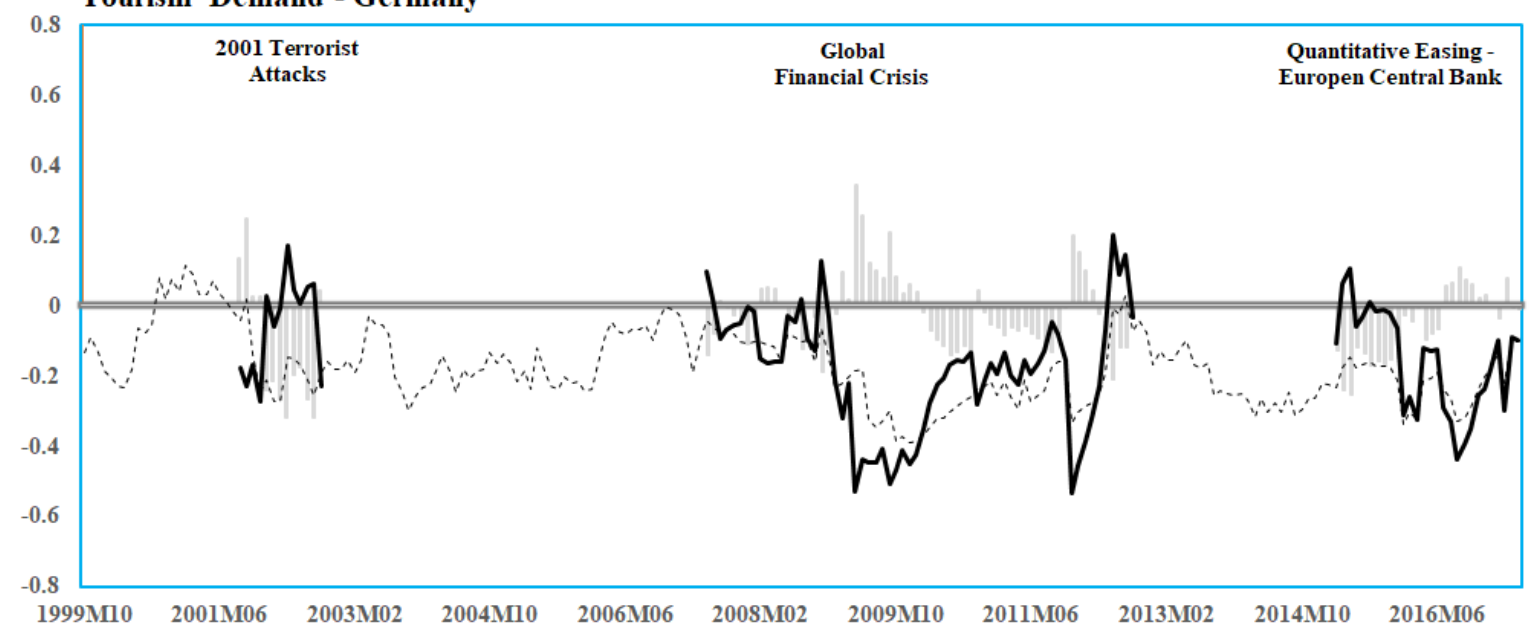

Tourism Demand - France

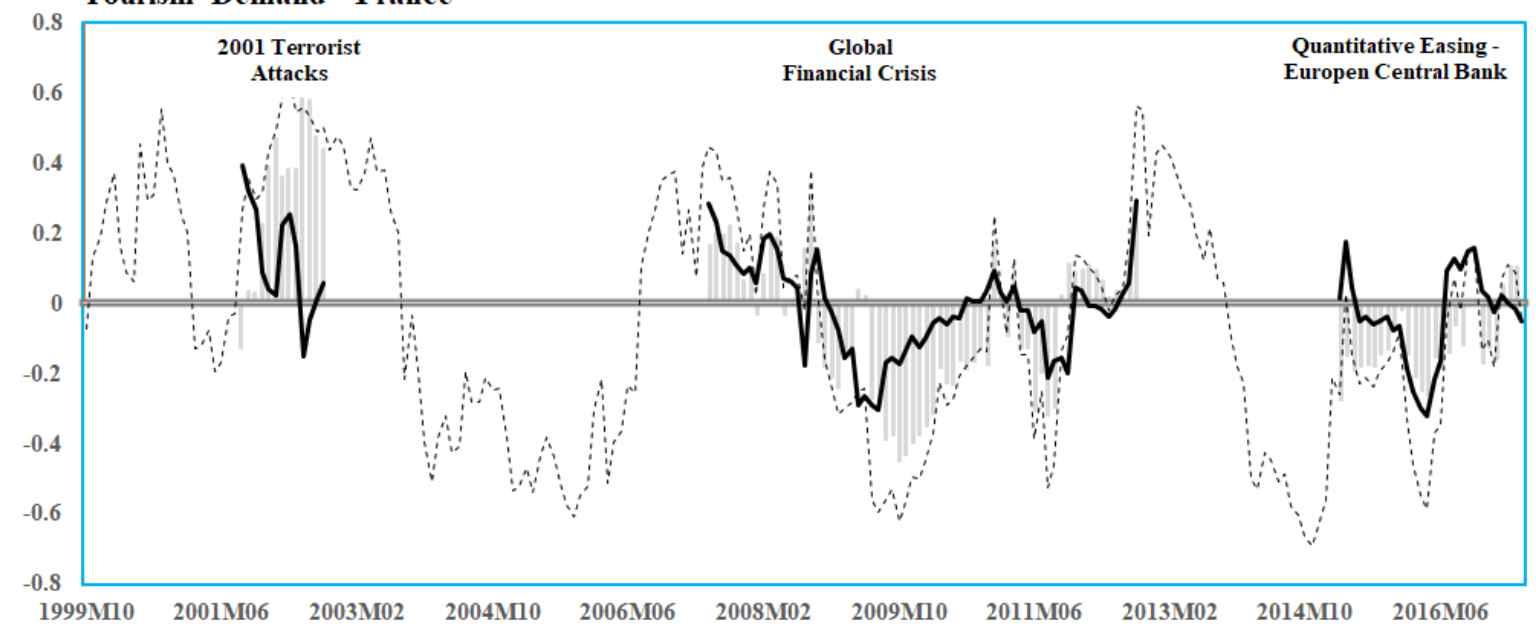


Figure 4: Continued

Tourism Demand - United Kingdom

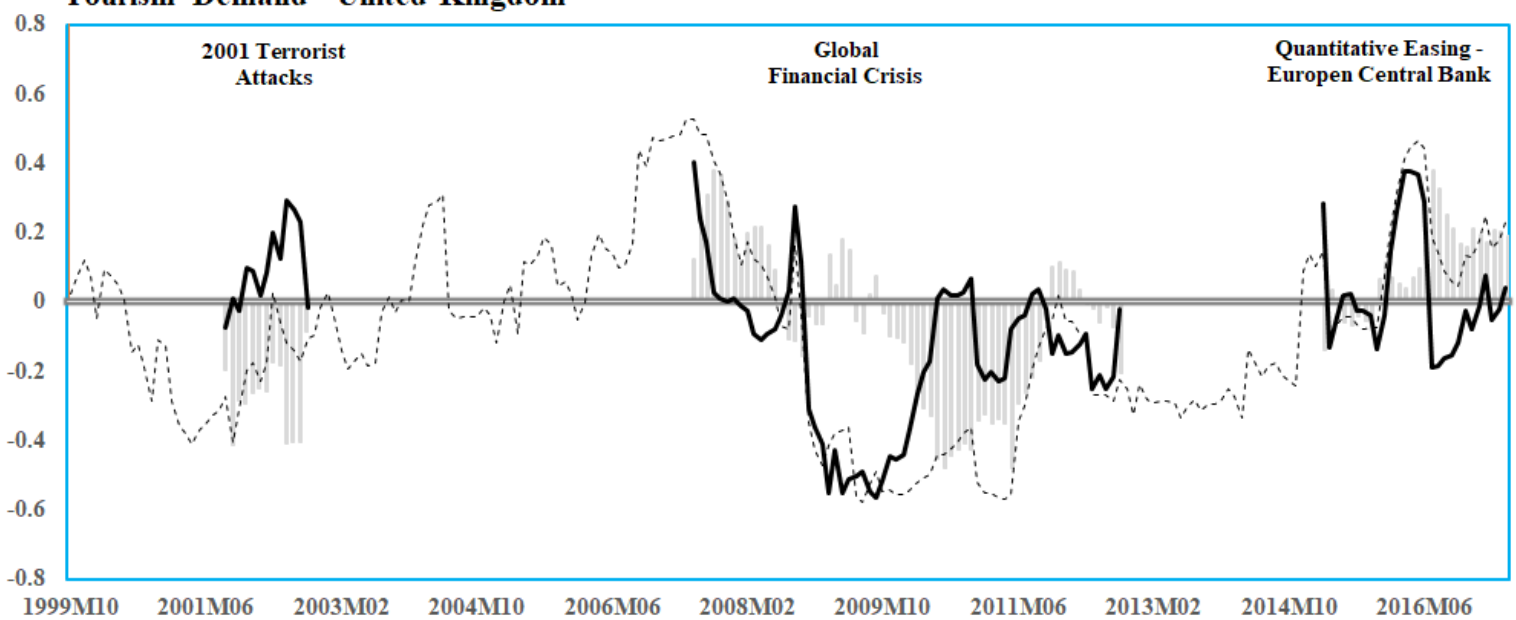

Tourism Demand - Italy

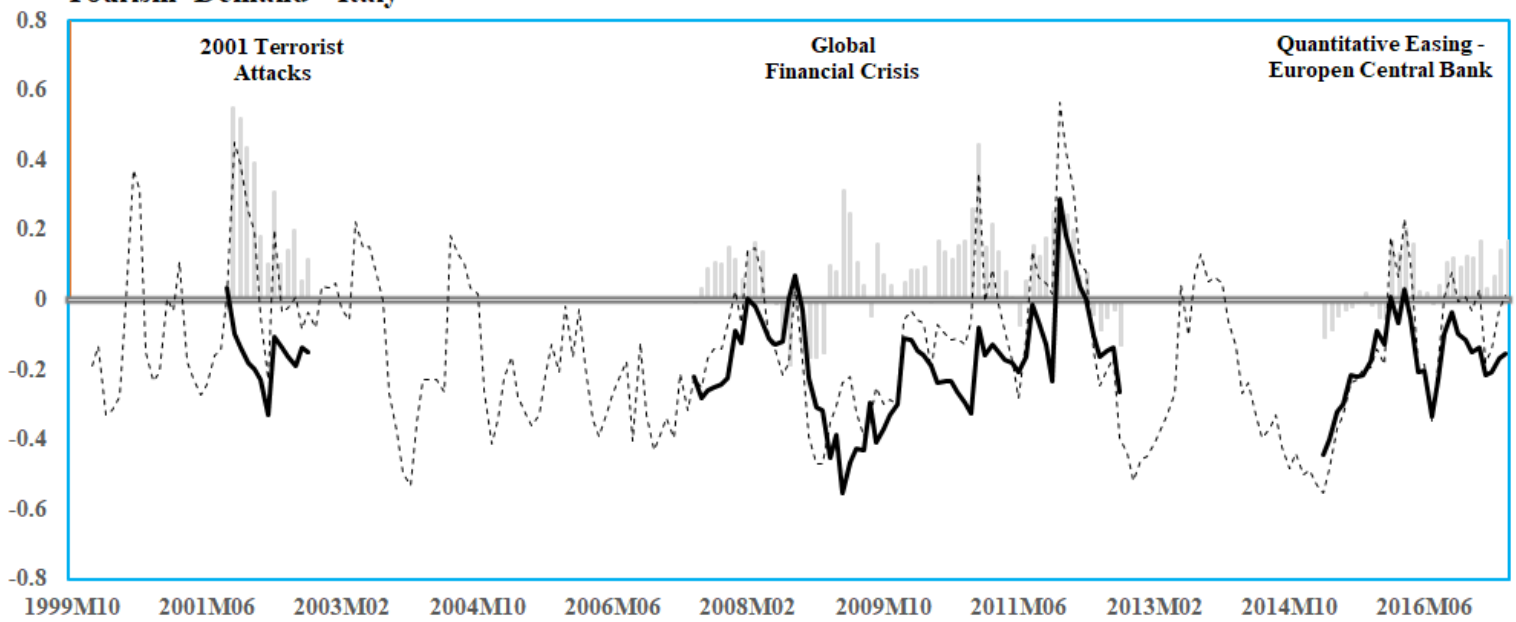

Tourism Demand - Netherlands

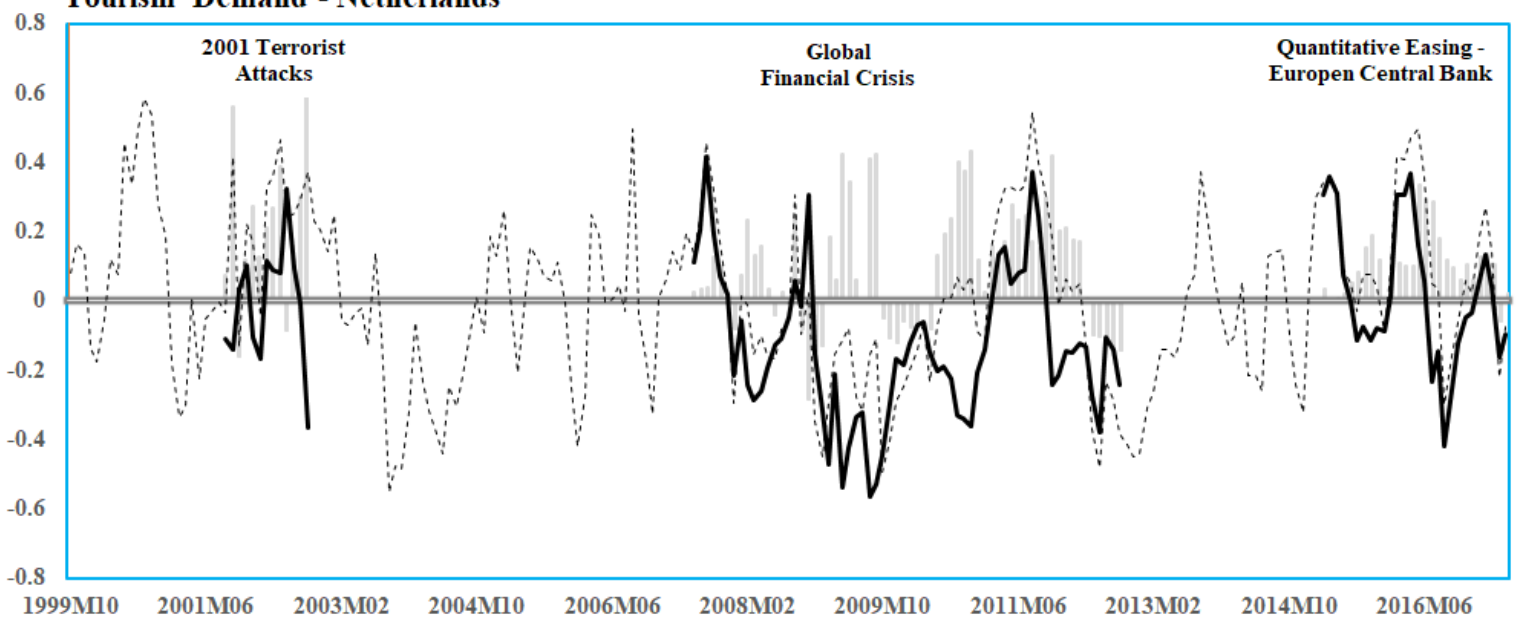

Note: The dashed line represents time varying correlation estimates of the tourism-expected economic growth relationship; the solid black line denotes the DCC estimates after controlling for the 2001 terrorist attacks, the Global Financial Crisis and the ECB's Quantitative Easing period; the grey bars measures the effect of the aforementioned events on the said relationship (i.e. the difference between the dashed and solid lines). 